\title{
On arising nanohydrides in reduced alkaline solution
}

\author{
Alexander L. Shimkevich \\ NRC “Kurchatov Institute”, Kurchatov Sq., Moscow, Russia
}

Email address:

shall@dhtp.kiae.ru

\section{To cite this article:}

Alexander L. Shimkevich. On Arising Nanohydrides in Reduced Alkaline Solution. American Journal of Modern Physics. Vol. 2, No. 4, 2013, pp. 185-189. doi: 10.11648/j.ajmp.20130204.11

\begin{abstract}
Studying electron properties of liquid water in the frame of band theory shows that obtaining its non-stoichiometric state is a simple way to vary physical and chemical properties, and changing a Reduction-Oxidation (RedOx) potential of any aqueous solution. In this connection, Fermi level in the band gap, as a measurable characteristic of non-stoichiometric liquid water, is the most convenient energy for monitoring and managing its RedOx potential. The hypo-stoichiometric state, $\mathrm{H}_{2} \mathrm{O}_{1-z}$, of liquid water is realized when the position of Fermi level is shifted to the bottom of conduction band. This state can be fixed by micro emulsifying gaseous hydrogen in liquid water or by electro-reducing the alkaline solution (catholyte) with possible forming alkaline (A) nanohydrides $\left(\mathrm{AH} \cdot \mathrm{H}_{2} \mathrm{O}\right)_{n}$. As strong reducers, they can be quasi-stable in the aqueous solution and be an effective means for holding the negative RedOx potential of liquid water.
\end{abstract}

Keywords: RedOx Potential, Fermi Level, Liquid Water, Hypo-stoichiometric State, Alkaline Solution, Catholyte, Nanohydrides

\section{Introduction}

In contrast to the generally accepted picture of liquid water as an ensemble of hydrogen-bonded tetrahedrons, there are found [1,2] many asymmetrically hydrogen-bonded molecules with only two well-defined $\mathrm{H}-$ bonds donating and accepting a proton. At the same time, free electrons do not exist in aqueous solution because it is a dielectric with a broad band gap, $\varepsilon_{\mathrm{g}}$. An electron lost by one species $\left(\operatorname{Red}_{1}\right)$ is gained by another $\left(\mathrm{Ox}_{2}\right)$ immediately in the reaction: $\mathrm{Red}_{1}+\mathrm{Ox}_{2} \rightarrow \mathrm{Ox}_{1}+\mathrm{Red}_{2}$.

Therefore it is useful for liquid water as a compound of variable composition to define a quantity called Fermi level, $\varepsilon_{\mathrm{F}}[3,4]$, as the electrochemical potential which indicates the tendency of liquid water to donate or accept the proton. If $\varepsilon_{\mathrm{F}}$ is low, there is a strong tendency for this condensed matter to donate protons, i.e. it is reducing.

Opposite, if Fermi level in liquid water is high, there is the strong tendency for it to accept protons when this matter is oxidizing.

Variation of $\varepsilon_{\mathrm{F}}$ by an external effect (for example, electrolysis) can facilitate forming a non-stoichiometric state, $\mathrm{H}_{2} \mathrm{O}_{1 \pm z}$, of liquid water and, obviously, change its physical and chemical properties as well as the Reduction-Oxidation (RedOx) potential of any aqueous solution.
Such the aspects of liquid water in hypo-stoichiometric state as the reduced one in electrochemical cell (catholyte) are the subjects of this paper.

\section{A Band Model for Liquid Water}

Fermi level is the most energy orbital occupied by electrons at zero temperature. The lower energy ones of atoms and molecules are combined and form a band called the valence band, and the higher energy orbitals are combined to form a band called the conduction band. Fig. 1 shows the experimental data of band structure in liquid water[5].

One can see that Fermi level is exactly in the middle of the band gap, $\varepsilon_{\mathrm{g}}=4.5 \mathrm{eV}$, between the conduction and valence bands. The value of $\varepsilon_{\mathrm{F}}=2.25 \mathrm{eV}$ corresponds to the stoichiometric state, $\mathrm{H}_{2} \mathrm{O}$, of liquid water.

The hypo-stoichiometric state, $\mathrm{H}_{2} \mathrm{O}_{1-z}$, is realized when the position of Fermi level in the band gap is shifted to the bottom of conduction band, for example, by nano-emulsifying gaseous hydrogen in liquid water [4].

Opposite, the hyper-stoichiometric state, $\mathrm{H}_{2} \mathrm{O}_{1+z}$, of liquid water can be realized by shifting Fermi level in the band gap down to the top of valence band in emulsifying water with oxygen nano-bubbles. 


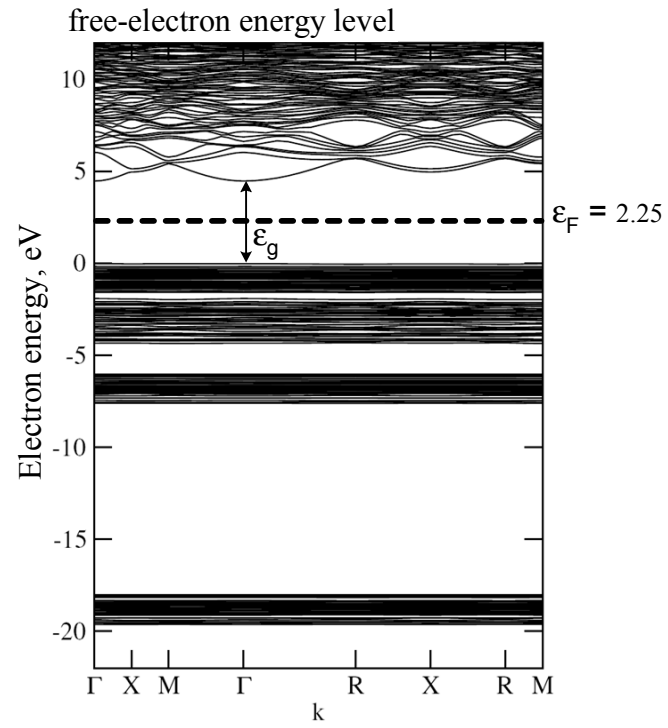

Figure 1. The mixed Brillion bands of liquid water in stoichiometric state (Fermi level, $\mathcal{E}_{F}$, in the middle of the band gap, $\varepsilon_{g}$ ); zero electron energy at the top of the valence band.

Thus, Fermi level is the very important electrochemical characteristic of aqueous solutions as an indicator showing how allowed energy states are occupied by electrons in liquid water[4]. It is illustrated by Fig. 2 where such the electron occupation is shown for assumed hydronium (b) and hydroxide (c) levels in the band theory as a function of Fermi level in the band gap of liquid water.

Fig. 2a shows that the hydroxide levels are all occupied and the hydronium ones are all vacant when Fermi level is in the middle between them. Electrons occupy the assumed hydronium energy state (Fig. 2b) when Fermi level approaches this state since liquid water becomes hypo-stoichiometric $\left(\mathrm{H}_{2} \mathrm{O}_{1-z}\right)$ as a result of decomposition reaction

$$
\mathrm{H}_{3} \mathrm{O}^{+}+\mathrm{OH}^{-}+\mathrm{H}_{2} \mathrm{O} \rightarrow(1 / 2) \mathrm{O} 2^{\uparrow}+2 \mathrm{H}_{3} \mathrm{O}
$$

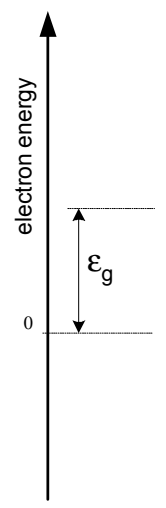

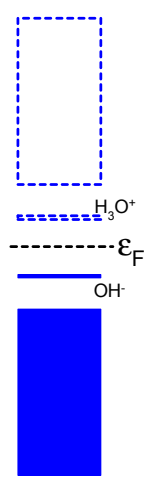
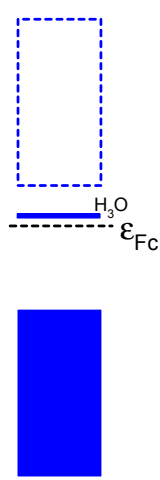
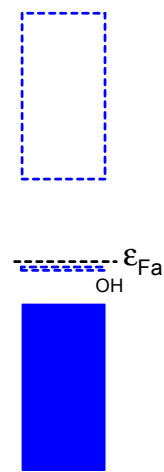

C

Figure 2. Electron energy diagrams for liquid water in the stoichiometric state (a), the hypo-stoichiometric one (b) as a catholyte with Fermi level, $\mathcal{E}_{F c}$ and the hyper-stoichiometric state $(c)$ as an anolyte $\left(\varepsilon_{F a}\right)$; the blue boxes are energy levels occupied by electrons and white boxes are unoccupied energy levels.
The reaction (1) decreases the concentrations of hydronium and hydroxide ions $\left(\left[\mathrm{H}_{3} \mathrm{O}^{+}\right],\left[\mathrm{OH}^{-}\right]\right)$in liquid water against to them in it for the stoichiometric state[6]:

$$
[\mathrm{H} 3 \mathrm{O}+] \cdot[\mathrm{OH}-]=\mathrm{Kw} \sim 10-14 \text { at } 300 \mathrm{~K} \text {. }
$$

Indeed, the number of electrons per allowed quantum state, $\varepsilon_{\mathrm{H} 3 \mathrm{O}}$, of donors $\left(\mathrm{H}_{3} \mathrm{O} \rightarrow \mathrm{H}_{3} \mathrm{O}^{+}+\mathrm{e}^{-}\right)$and $\varepsilon_{\mathrm{OH}}$ of accepters $\left(\mathrm{OH}+\mathrm{e}^{-} \rightarrow \mathrm{OH}^{-}\right)$in liquid water is given by Fermi-Dirac distribution which can be simplified to Maxwell-Boltzmann one [7]:

$$
\begin{gathered}
{[\mathrm{H} 3 \mathrm{O}]=([\mathrm{H} 3 \mathrm{O}]+[\mathrm{H} 3 \mathrm{O}+]) \mathrm{KH} 3 \mathrm{O} /(1+\mathrm{KH} 3 \mathrm{O}),} \\
{[\mathrm{OH}]=([\mathrm{OH}]+[\mathrm{OH}-]) \mathrm{KOH} /(1+\mathrm{KOH})}
\end{gathered}
$$

where $K_{\mathrm{H} 3 \mathrm{O}} \equiv \exp \left(\left(\varepsilon_{\mathrm{F}}-\varepsilon_{\mathrm{H} 3 \mathrm{O}}\right) / k_{\mathrm{B}} T\right), K_{\mathrm{OH}} \equiv \exp \left(\left(\varepsilon_{\mathrm{OH}}-\varepsilon_{\mathrm{F}}\right) / k_{\mathrm{B}} T\right)$, $T$ is Kelvin temperature, and $k_{\mathrm{B}}$ is Boltzmann constant.

At room temperature, $k_{\mathrm{B}} T$ is about $0.025 \mathrm{eV}$ therefore $K_{\mathrm{H} 3 \mathrm{O}} \sim 2 \cdot 10^{-11}$ for $\left(\varepsilon_{\mathrm{H} 3 \mathrm{O}}-\varepsilon_{\mathrm{F}}\right)=0.615 \mathrm{eV}$, that is only 20 of trillion hydronium ions are activated as electron donors, $\mathrm{H}_{3} \mathrm{O}$, in stoichiometric water $\left(\varepsilon_{\mathrm{F}}=2.25 \mathrm{eV}\right.$, see Fig. 1).

For non-stoichiometric water, $\mathrm{H}_{2} \mathrm{O}_{1 \pm z}$ (see Fig. 2b, c) with $z$ defined by equation [4]

$$
z=\left(1+\sqrt{K_{\mathrm{OH}} / K_{\mathrm{H} 3 \mathrm{O}}}\right)^{-1}-\left(1+\exp \left(\varepsilon_{\mathrm{F}} / k_{\mathrm{B}} T\right)\right)^{-1}
$$

the correlation (2) is transformed to

$$
\left[\mathrm{H}_{3} \mathrm{O}^{+}\right] \cdot\left[\mathrm{OH}^{-}\right]=K_{\mathrm{w}} /\left(1+K_{\mathrm{H} 3 \mathrm{O}}\right)\left(1+K_{\mathrm{OH}}\right)
$$

It means that the strongly reduced $\left(\varepsilon_{\mathrm{F}}>\varepsilon_{\mathrm{H} 3 \mathrm{O}}\right)$ pure water practically should not include hydronium ions as well as the strongly oxidized $\left(\varepsilon_{\mathrm{F}}<\varepsilon_{\mathrm{OH}}\right)$ one not include hydroxide ions. Therefore the first medium as quasi equilibrium phase consist of clusters $\left(\mathrm{H}_{3} \mathrm{O}\right)_{n}$ that are hydrogen nano-bubbles in fact. Respectively, the second one is nano-emulsified oxygen in oxidized water by the clusters, $(\mathrm{OH})_{n}$.

It is known [8] that the RedOx potential, $E_{\mathrm{h} 1}$, of the pure water decomposition on reaction

$$
\mathrm{H} 3 \mathrm{O}++2 \mathrm{e}^{-} \rightarrow \mathrm{H} 2 \uparrow+\mathrm{OH}_{-}-
$$

is equal to $-0.41 \mathrm{~V}$ at $\mathrm{pH}=7$ and is determined by the hydrogen electrode[9]. An alternative decomposition reaction

$$
\mathrm{H} 2 \mathrm{O}+\mathrm{OH}-\rightarrow(1 / 2) \mathrm{O} 2 \uparrow+\mathrm{H} 3 \mathrm{O}++2 \mathrm{e}^{-}
$$

occurs at $E_{\mathrm{h} 2}=0.82 \mathrm{~V}$ at the same conditions.

It is clear that the half-difference of these RedOx potentials, $\left(E_{\mathrm{h} 2}-E_{\mathrm{h} 1}\right) / 2=0.615 \mathrm{~V}$, defines the position of Fermi level in the stoichiometric water (see Fig.2a). Therefore these RedOx potentials correspond to assumed electron levels, $\varepsilon_{\mathrm{H} 3 \mathrm{O}}$ and $\varepsilon_{\mathrm{OH}}$, in the band gap of liquid water.

In order to occupy the first, it is necessary shifting Fermi level to $\varepsilon_{\mathrm{H} 3 \mathrm{O}}=2.9 \mathrm{eV}$. In order to vacate the second, it is necessary shifting Fermi level down to $\varepsilon_{\mathrm{OH}}=1.6 \mathrm{eV}$. 


\section{The Bands of Alkaline Solution}

For an alkaline base, $\mathrm{AOH}$, completely ionized in water, its band structure will include a vacant metal state, $\mathrm{A}^{+}$, near the bottom of conduction band as it is shown in Fig. 3 .

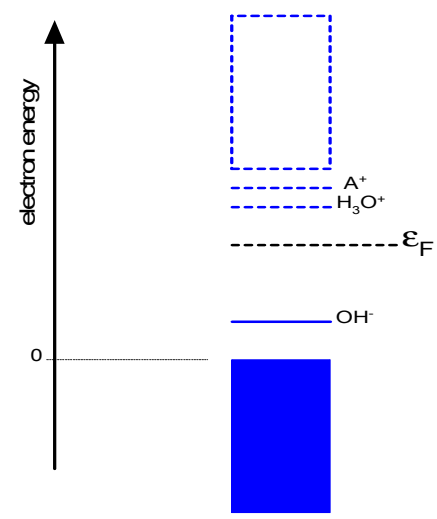

Figure 3. Band structure of alkaline solution with energy level, $\boldsymbol{\varepsilon}_{A}$, for alkali-metal (A) electron donors in liquid water; the blue boxes are energy levels occupied by electrons and white boxes are unoccupied energy levels.

In this case, the equation (6) is to take a correction of the dissolved metal cations into account the concentration of electron donors $\left[\mathrm{H}_{3} \mathrm{O}\right]$ under the conditions:

$$
[\mathrm{H} 3 \mathrm{O}+]<<[\mathrm{A}+] \sim[\mathrm{OH}-] .
$$

The concentration of donors [A] in alkaline solution is given by distribution [7]:

$$
[\mathrm{A}]=([\mathrm{A}]+[\mathrm{A}+]) \mathrm{KA} /(1+\mathrm{KA}),
$$

where $K_{\mathrm{A}} \equiv \exp \left(\left(\varepsilon_{\mathrm{F}}-\varepsilon_{\mathrm{A}}\right) / k_{\mathrm{B}} T\right)$ and $\varepsilon_{\mathrm{A}}$ is the assumed electron energy level in the band gap of liquid water for the alkali metal (A) as a base impurity in the aqueous solution.

In combining equations (2)-(4), (9), and (10) for the reduced aqueous solution of $\mathrm{AOH}$, we can obtain the concentrations of hydronium states occupied and unoccupied by electrons:

$$
\begin{gathered}
{[\mathrm{H} 3 \mathrm{O}]=[\mathrm{H} 3 \mathrm{O}+] \cdot \mathrm{KH} 3 \mathrm{O},} \\
{[\mathrm{H} 3 \mathrm{O}+] \sim[\mathrm{A}+] \cdot \mathrm{Kw} /(1+\mathrm{KH} 3 \mathrm{O})(1+\mathrm{KA}),}
\end{gathered}
$$

that are simplified at $\varepsilon_{\mathrm{H} 3 \mathrm{O}}<\varepsilon_{\mathrm{F}}<\varepsilon_{\mathrm{A}}$ :

$$
\begin{gathered}
{[\mathrm{H} 3 \mathrm{O}] \sim[\mathrm{A}+] \cdot \mathrm{Kw},} \\
{[\mathrm{H} 3 \mathrm{O}+]=0}
\end{gathered}
$$

when all hydronium states are occupied by electrons. It means that the strongly reduced alkaline solution has no free protons for cathode generating gaseous hydrogen in the electrochemical cell with this solution.

\section{The Polarization of Galvanic Cathode}

It is known that two phases are in equilibrium if their electrochemical potentials are equal. If they are different, charge redistribution between metal electrode and aqueous solution is required in order to equilibrate the directly contacting phases. In this case (see Fig.4), the aqueous part of the electric double layer (DL) always is negative at the interface between any metal electrode and liquid water.

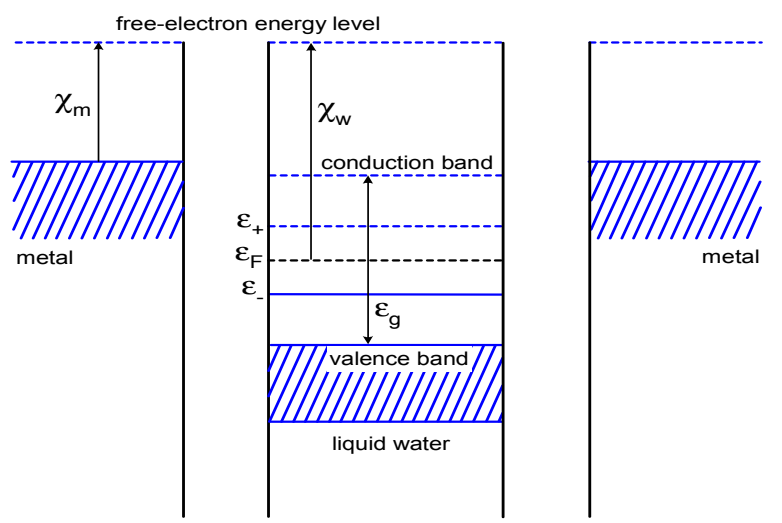

Figure 4. Band structure of separated metal electrodes and liquid water: $\chi_{m}$ is a work function of electrodes; $\chi_{w}$ is work function of liquid water; $\varepsilon_{g}$ is its band gap and $\varepsilon_{F}$ is Fermi level; $\mathcal{E}_{+}$is energy level of vacant hydronium level $\left(\mathrm{H}_{3} \mathrm{O}^{+}\right)$and $\varepsilon$ is energy level of occupied hydroxide level $\left(\mathrm{OH}^{-}\right)$.

Indeed as seen in Fig. 1, the work function, $\chi_{w}$, of liquid water (in the stoichiometric state) approximately is equal to $9.8 \mathrm{eV}$ which is more than the work function, $\chi_{\mathrm{m}}$, of all the metal electrodes because the most work function of platinum, $\chi_{\mathrm{Pt}}$, only is equal to $\sim 6.4 \mathrm{eV}$.

Therefore the band structure of electrodes and aqueous electrolyte in the broken electrochemical cell will be as is shown in Fig.5. The negative DL part on the side of liquid water is formed by concentrating hydroxide ions $\left(\mathrm{OH}^{-}\right)$near the metal electrodes and strongly deforms the band structure of liquid water near the electrodes.

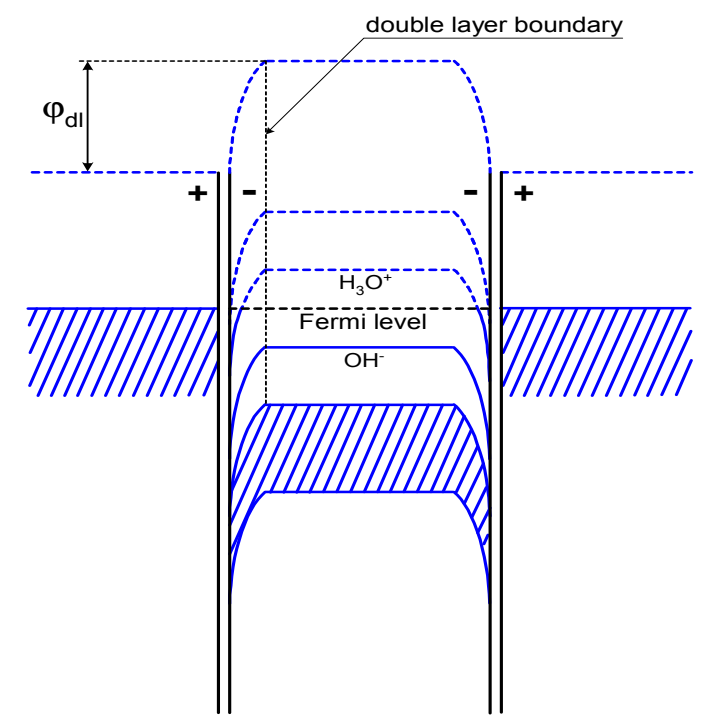

Figure 5. Band structures of the metal (Pt) electrodes and liquid water as the electrolyte in direct contact between them: $\varphi_{d l}$ is the value of $D L$ potential; vertical dotted line is the boundary of the negatively charged DL electrolyte part. 
One can see that the hydronium energy state, $\varepsilon_{\mathrm{H} 3 \mathrm{O}}$, is occupied by electrons in the liquid part of double layer since here Fermi level is higher than the hydronium one when Fermi levels of contacting phases (the metal electrode and liquid water) are equating in equilibration of their electrochemical potentials. Therefore the concentration of hydronium ions practically is equal to zero in this layer.

In this connection, we think that an applied external potential to the electrochemical cell with stoichiometric water in the closed circuit will strongly polarize its cathode.

Indeed, the negative charge formed by high density of hydroxide ions in aqueous DL part near the cathode inhibits their generation in possible catholic reactions:

$$
\begin{gathered}
\mathrm{H} 3 \mathrm{O}+\mathrm{e}^{-} \rightarrow \mathrm{H} 2 \uparrow+\mathrm{OH}^{-}, \\
2 \mathrm{H} 2 \mathrm{O}+\mathrm{e}^{-} \rightarrow \mathrm{H} 3 \mathrm{O}+\mathrm{OH}^{-}
\end{gathered}
$$

It increases Fermi level in aqueous solution to the bottom of conduction band (as it is shown in Fig.6) in order to decrease the value of DL potential, $\varphi_{\mathrm{dl}}$, and, consequently, the balanced concentration of $\mathrm{OH}^{-}$near the cathode by means of the half-cell reaction (16) and diffusion of $\mathrm{H}_{3} \mathrm{O}$ radicals into the bulk of liquid water.

In using the anode of such the electrochemical cell with an area essentially less than the catholic one, we will get a high anode polarization and as much as possible the anode over potential $\Delta_{3}>\Delta_{1}$. It will hold the high gradient of Fermi level in this space of the electrochemical cell (see Fig.6) and facilitate the anodic reaction

$$
\mathrm{H} 2 \mathrm{O}+\mathrm{OH}-\rightarrow(1 / 2) \mathrm{O} 2 \uparrow+\mathrm{e}^{-}+\mathrm{H} 3 \mathrm{O}
$$

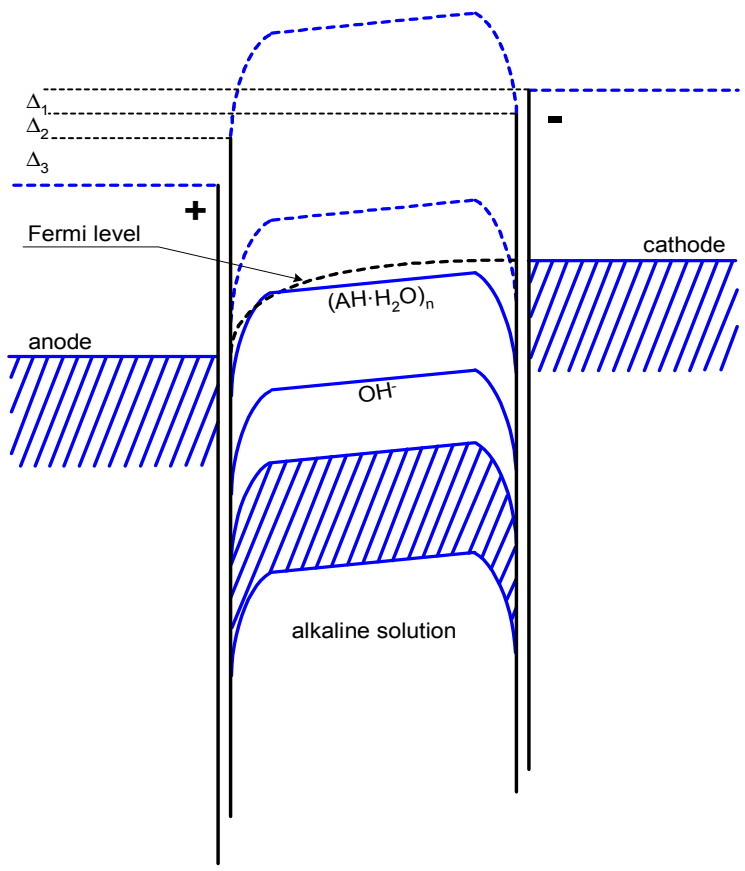

Figure 6. Band structure of electrochemical cell with strongly reduced alkaline solution as a liquid electrolyte: $\Delta_{1}$ is the cathode over potential; $\Delta_{2}$ is $I \cdot R$ drop in electrolyte; $\Delta_{3}$ is the anode over potential.

\section{Conclusions}

For facilitating the half-cell reaction (17), it is practical to use an alkaline solution in order to have high concentration of hydroxide ions in the hypo-stoichiometric water as it should be from equation (9).

Then the mode of electrochemical reduction of alkaline solution considered above may be effective method for obtaining a stable catholyte in the hypo-stoichiometric water where it is possible to develop the half-cell reaction (16) into gathering nanohydrides $\left(\mathrm{AH} \cdot \mathrm{H}_{2} \mathrm{O}\right)_{n}$ by accessory cathodic reaction

$$
\mathrm{nA}++\mathrm{nH} 3 \mathrm{O}+\mathrm{ne}-\rightarrow(\mathrm{AH} \cdot \mathrm{H} 2 \mathrm{O}) \mathrm{n}
$$

It is very important reaction since the free radical, $\mathrm{H}_{3} \mathrm{O}$, is the species with unpaired electron and therefore is highly reactive [10].

In order to start up the half-cell reaction (18), it is necessary organizing the electrochemical process for electro-reducing the alkaline solution so that Fermi level has been shifted to the bottom of conduction band by $\sim 4.5 \mathrm{eV}$ (see Fig. 1) and aqueous solution could be the strongly hypo-stoichiometric. Then the hydride ion $\left(\mathrm{H}^{-}\right)$as a good proton acceptor and $\mathrm{H}_{3} \mathrm{O}$ as electron donor will be mutually complementary in aqueous solution.

Thus, the hypo-stoichiometric state, $\mathrm{H}_{2} \mathrm{O}_{1-z}$, of liquid water is realized when the position of Fermi level, $\varepsilon_{\mathrm{F}}$, is near the bottom of conduction band. In this state, the pure liquid water can be lightly converted into nano-emulsified hydrogen solution and the alkaline solution - into aqueous colloid of hydrides. The stronger reducing alkaline solution is the smaller hydride particles are in it[11].

\section{Acknowledgements}

Author is pleased to the Russian Foundation for Basic Research for supporting this work (grant \# 13-08-00826a).

\section{References}

[1] Ph. Wernet et al., Science, vol. 304, p. 995, 2004.

[2] T. Tokushima et al., "High resolution X-ray emission spectroscopy of liquid water: the observation of two structural motifs", Chem. Phys. Letters, vol. 460, p. 387, 2008

[3] P.N. Alekseev, Yu.M. Semchenkov, A.L. Shimkevich, "Aqueous nanofluid as a two-phase coolant for PWR", Science and Technology of Nuclear Installations, Article ID 214381, 6 pages, 2012, doi: 10.1155/2012/214381.

[4] A.L. Shimkevich and I.Yu. Shimkevich, "On 2D water chemistry", in Proceedings of Nuclear Plant Chemistry Conference (NPC-2012), Paper \# P1-39-176, 2012.

[5] G. Galli, Electronic properties of water, University of California, Davis, http://angstrom.ucdavis.edu.

[6] M. Chaplin, Ionization of water, London: South Bank 
University, 2008.

[7] Ch. Kittel, H. Kroemer, Thermal physics, 2nd ed., San Francisco: W. H. Freeman, 1980. ISBN 978-0-7167-1088-2.

[8] http://www.lsbu.ac.uk/water/electrolysis.html.

[9] W.M. Clark, The determination of hydrogen ions, 2nd ed.,
Baltimore: Williams and Wilkins Co. USA, 1927.

[10] G.R. Buettner, F.Q. Schafer, "Free radicals, oxidants, and antioxidants", Teratology, vol. 62, p. 234, 2000.

[11] M. Chen et al., "Synthesis and self-organization of soluble monodisperse palladium nanoclusters", Journal of Colloid and Interface Science, vol. 287, p. 146, 2005. 